\title{
Introducción: Hacia un hispanismo (todavía más) queer ${ }^{1}$
}

\author{
Jorge Luis Peralta \\ Universidad Nacional de La Plata - CONICET \\ Łukasz Smuga \\ Uniwersytet Wrocławski
}

Poco más de veinte años han pasado desde que se comenzaron a publicar las primeras colecciones de estudios gais, lesbianos y queer centrados en el ámbito hispanohablante. Volúmenes como ¿Entiendes? Queer Readings, Hispanic Writings (Bergmann y Smith, 1995), Bodies and Biases (Foster y Reis, 1996), Sex and Sexuality in Latin America (Balderston y Guy, 1996), o Hispanisms and Homosexualities (Molloy y Mckee Irwin, 1998) constituyeron aproximaciones pioneras en las que reconocidos/as investigadores/as ${ }^{2}$ reflexionaban sobre cuestiones de género y sexualidad en contextos muy diferentes a aquellos en los que se producía la teoría queer. Uno de los debates iniciales orbitó, precisamente, en torno a las importaciones y usos de aparatos teóricos y herramientas metodológicas gestadas en $-\mathrm{y}$ sobre - realidades considerablemente alejadas de nuestros países (aunque la homogeneidad aparente de ese "nuestros" era y sigue siendo inevitablemente ficticia, habida cuenta de las múltiples diferencias entre, por un lado, España y Latinoamérica, y por otro, entre - y al interior - de las diversas regiones y países de habla hispana). Al hilo de esa polémica — cuyos ecos llegan hasta la actualidad (Rivas San Martín) - el corpus de investigación sobre el tema no ha dejado de incrementarse; a las colecciones de ensayos escritos en inglés no tardaron en sumarse otras elaboradas en español, o bilingües. También apareció, consecuentemente, una notable cantidad de monografías, con títulos tan relevantes como Teoría torcida (1998) de Ricardo Llamas, Un amor que se atrevió a decir su nombre (2000) de Norma Mogrovejo, Tropics of Desire (2000) de José Quiroga, Sueños de exterminio (2004) de Gabriel Giorgi, La salida del armario (2005) de Inmaculada Pertusa, Queer Transitions in Contemporary Spanish Culture (2007) de Gema Sánchez-Pérez, Feminismo, género y diferencia(s) (2008) de Nelly Richard, El laberinto queer (2008) de Susana López Penedo, Deseo y resistencia (2009) de Gracia Trujillo (2009), Nación marica (2009) de Juan Pablo Sutherland o Poses de fin de siglo (2012) de Sylvia Molloy, por

${ }^{1}$ La edición del monográfico de InterAlia: A Journal of Queer Studies titulado "Entre otros/as. Perspectivas queer en el mundo hispánico/Among Others. Queer Perspectives in Hispanic World", al igual que este y otros trabajos que en él aparecen, forman parte del proyecto FEM2015-69863-P MINECO-FEDER ("Diversidad de género, masculinidad y cultura en España, Argentina y México"), del programa español de fomento de la investigación científica y técnica de excelencia.

${ }^{2}$ A lo largo de la presente introducción, y a fin de emplear un lenguaje inclusivo, optamos por las formas gramaticales "os/as". En el resto de artículos que componen el dossier, sin embargo, hemos respetado la decisión de cada autor/a de utilizar las formas que creyeron convenientes. 
nombrar solo algunas contribuciones de una amplia constelación que incluye muy diversos objetos de análisis y perspectivas disciplinarias.

Si bien resulta indudable, como señaló Daniel Balderston (2004), que hubo una "conspiración de silencio" por parte de la historiografía y crítica latinoamericanas respecto de las representaciones literarias de sexualidades disidentes, a lo largo de los años ese vacío bibliográfico se ha ido cubriendo paulatinamente, tanto en lo que respecta a estudios literarios y culturales, como a investigaciones producidas en el marco general de las ciencias sociales y las humanidades. En rigor, el arraigo de los estudios LGTBQ ha sido más firme y sostenido en campos disciplinares como la sociología, la antropología, la historiografía o la psicología, que en el ámbito de la investigación sobre literatura, todavía reticente a incorporar estas perspectivas teórico-críticas. Mérida Jiménez ("Queerencias" 12) sugería que esa reticencia obedece, en el caso de las universidades españolas, al pánico derivado de "razones patrias y patriarcales", un argumento que podría hacerse extensivo a los países latinoamericanos, más allá de las particularidades que el machismo, la misoginia y diversas fobias (trans-, lesbo-, homo-) asumen en cada uno de ellos, y de sus espacios académicos e institucionales.

El aspecto terminológico ha ocupado un lugar de relevancia en el marco de los estudios LGTBQ hispánicos. Ni las palabras ni el uso que se hace de ellas son neutrales, razón por la cual las significaciones e interpretaciones activadas dependerán de su elección. Los títulos de algunas investigaciones realizadas en los últimos años vacilan entre la separación o yuxtaposición de "gay", "lésbico" y "queer", terminología que remite por una parte a los gay and lesbian studies —surgidos en la década de los setenta- y por otra a los queer studies, aparecidos a fines de la década de los ochenta. Existen, así, estudios que prefieren "gay" y "lésbico/lesbiano" (Foster, Gay and Lesbian Themes; Martínez Expósito; Ingenschay); otros que optan por hablar de "sexualidades", "homosexualidades", identidades o culturas "homoeróticas", "perspectivas sexogénericas" (Balderston y Guy; Molloy y McKee Irwin; Foster Producciones homoeróticas y Ensayos sobre culturas; Balderston; Balderston y Quiroga; Balutet; Sutherland); una tercera tendencia se decide por la coexistencia de "gay", "lésbico" y "queer" (Martínez) y una cuarta remite únicamente a "queer" (Foster Sexual Textualities; Chávez-Silverman y Hernández; Rodríguez; Amícola; Sibbald y Cornejo Parriego; Martinelli). Esta variedad de combinaciones terminológicas manifiesta la amplitud y diversidad de criterios con que los/as investigadores/as han abordado el estudio de las identidades sexuales no hegemónicas y las manifestaciones culturales vinculadas con ellas.

En relación con el término queer, la propuesta inicial de Ricardo Llamas (xi) de traducirlo por "torcido" no tuvo una acogida amplia. David Córdoba García (21-22) defendió el uso de la palabra original ofreciendo cuatro motivos: su generalización en el ámbito del activismo y de la —por entonces escasa - teoría gay y lesbiana española; la valoración de conexiones con comunidades gais y lesbianas de otras latitudes, por encima de las especificidades nacionales; la neutralidad genérica del término, que alude tanto a sujetos femeninos como masculinos y, por extensión, a diversas identidades no normativas (bisexuales, transexuales, transgéneros, etc.); finalmente, la conservación del significado de "raro" o "extraño", que ilustra la voluntad de apartamiento de la norma sexual. Consciente, sin embargo, de que el uso del término en inglés implica el 
despojamiento de su incorrección política, el crítico valoró posibles reformulaciones en español, tales como "teoría maricona", "teoría bollera", "teoría maribollo", etc.

En la introducción a Sexualidades transgresoras, primera antología de ensayos norteamericanos de teoría queer traducidos al español, Mérida Jiménez se refería al problema de la importación de la palabra queer: "no existe un vocablo equivalente en español que recoja la mezcla de acepciones ni que permita su natural transformación lingüística en sustantivo, adjetivo o verbo" (19), razón por la cual optaba por mantener la palabra original "a sabiendas de la incomodidad que puede provocar en muchos/as lectores/as". El debate sobre la traducibilidad e intraducibilidad de queer fue retomado, entre otros/as, por Amy Kaminsky y Brad Epps en sendos artículos incluidos en un dossier de la Revista Iberoamericana compilado por Luciano Martínez (2008), quien sostuvo que la reflexión sobre estas cuestiones lingüísticas había estado ausente en los volúmenes antológicos previos debido a que estaban escritos en inglés. Kaminsky sugirió el neologismo "encuirar" como posible traducción para el verbo to queer: "reminiscente del verbo encuerar y evocador del acto de desnudar, encuirar significa des-cubrir la realidad, retirar la capa de la heteronormatividad" (879). Para esta investigadora, la incorporación del término no ha sido excesivamente problemática, aunque señaló que "el encabalgamiento adjetival 'lésbico-gay/ queer' es un indicio semántico de la condensación de una trayectoria teórica que en los estudios literarios y culturales anglosajones tuvo un proceso mucho más lento" (881). Su propuesta buscó denominar el intento de llevar lo queer al hispanismo y el hispanismo a lo queer tal como habían postulado Molloy y McKee Irwin (xi). Kaminsky expuso las dificultades de esta empresa en contextos donde todavía resultaba necesario analizar la presencia de lo gay y de lo lésbico, categorías identitarias que queer viene a cuestionar y deconstruir. Buscó, en definitiva, una reconciliación entre lo queer como activismo y como práctica académica en un ámbito en el cual ni uno ni otra han tenido el mismo desarrollo que en los países de los cuales proviene dicha teoría. Epps, por su parte, afirmó que la internacionalización del término sería doblemente efectiva, a su juicio, si se atendieran no solo las aportaciones anglófonas y estrictamente académicas. Al igual que Córdoba García, Epps subrayó que cuando se usa en español, queer pierde la historia y el carácter reivindicativo que poseía originalmente: "En un contexto no angloparlante [...] el término 'queer' no es ni callejero ni coloquial sino foráneo, extraño y nuevo incluso, y tiende a usarse de manera casi exclusivamente académica y/o teórica: es, en breve, una palabra cuya fuerza reivindicativa, elaborada en los Estados Unidos y otros países anglófonos, precede toda memoria de su carga injuriosa (memoria, por otra parte, ligada a textos y contextos en inglés)" (899). Además de su significado de "extraño" o "raro", queer se empleaba como injuria o insulto dirigido a los homosexuales: por este motivo, la resignificación del término resultaría impracticable en español. Ante esta situación, algunos colectivos identificados con lo queer han optado por la etiqueta "transmaricabollo". También está alcanzando importante difusión el término "transfeminismo", como explica Miriam Solá en una reciente colección de ensayos sobre el tema: "Este 'nuevo' vocablo materializa la necesidad política de hacerse cargo de la multiplicidad del sujeto feminista. Pero también es un término que quiere situar al feminismo como un conjunto de prácticas y teorías en movimiento que dan cuenta de una pluralidad de opresiones y situaciones, mostrando así la complejidad de los nuevos retos a los que debe enfrentarse y la necesidad de una resistencia conjunta en torno al género y a la sexualidad" (19-20). 
La cuestión de los términos y de su traducción constituye solo un aspecto de un debate arduo con respecto a la conveniencia o inconveniencia, oportunidad o interés, de importar y de adaptar a los países hispanohablantes un aparato teórico concebido en otras latitudes, cuyas coordenadas políticas, sociales, económicas son forzosamente muy distintas. Entre los primeros que llamaron la atención sobre este aspecto ya se encontraban Emilie Bergmann y Paul Julian Smith, quienes en la introducción a su antología ¿Entiendes? afirmaban: "[c]ualquier apropiación de teoría europea o norteamericana, por lo tanto, será siempre una incorporación: un proceso en el cual lo extranjero es introducido en y absorbido por el cuerpo de textos e intérpretes hispánicos" (2). Esta idea de incorporar la teoría europea y norteamericana fue problematizada por otros estudiosos. De acuerdo con Alfredo Martínez Expósito, la introducción del hispanismo en los estudios gais sería un asunto todavía pendiente, pues "se opera de manera deductiva y se aplica una teoría prefabricada a cualquier tipo de objeto cultural" (48). Robert Richmond Ellis, en una línea similar, sostuvo que "la teoría queer ha sido constreñida por su foco en paradigmas angloamericanos y europeos de género y sexualidad" (3). La necesidad de una mirada queer sobre la literatura y la cultura iberoamericanas había sido manifestada con anterioridad por Sylvia Molloy y Robert McKee Irwin en Hispanisms and Homosexualities, que ya desde el título anunciaba la voluntad de un enfoque plural: "esta colección querría introducir los hispanismos dentro de las homosexualidades, y las homosexualidades dentro de los hispanismos, querría proponer lecturas queer de literaturas y culturas españolas y latinoamericanas" (xvi). Después de casi dos décadas durante las cuales el diálogo entre los hispanismos y las homosexualidades se ha ido intensificando, podría afirmarse que las reflexiones provenientes del extranjero han servido como un marco general a partir del cual pensar los problemas específicamente latinoamericanos. Esa es también la posición de José Javier Maristany, quien en un artículo centrado en las derivas latinoamericanas del término queer, arribaba a la siguiente conclusión:

la masiva apropiación del vocablo queer en ámbitos y producciones diversos, no responde a un mero afán de copia por parte de sectores intelectuales y militantes, o una moda reservada a ciertos grupos privilegiados - gays y lesbianas blancos salidos de clases medias-; por el contrario, ese término permite mantener un cierto pudor que se vuelve estratégico en nuestro contexto socio-cultural al momento de pensar desarrollos académicos y acciones militantes: un "espacio queer" es, de algún modo, una pantalla que contrabandea un coeficiente de abyección cargado de una inquietante ambigüedad en cada enunciación puesto que es un significante vacío para los hispanohablantes, significante para el que estamos elaborando y adecuando un contenido en cada utilización que de él hacemos. A veces no sabemos muy bien de qué hablamos cuando lo utilizamos, pero somos conscientes de que no es la mera suma de todos los significados que pueden reposar bajo su sombra (109).

La frecuencia e intensidad de los usos y (re)apropiaciones de queer en España y Latinoamérica indicarían, a esta altura, que el término ha pasado a formar parte de nuestro vocabulario crítico y activista, más allá de que puedan persistir ciertas resistencias o tensiones, o de que sea necesario, como argumenta Felipe Rivas San Martín, interrogar y cuestionar "el establecimiento de lo queer como referente modélico y parámetro de lectura de las prácticas y discursos críticos en los sectores 
de la periferia sexual latinoamericana" (60). Lucas Martinelli, en el prólogo a una reciente compilación de ensayos sobre arte latinoamericano, llega a alertar, en este sentido, sobre el peligro de que queer se convierta en un lugar seguro dentro de la academia, por lo que invita a "construir nuevos conceptos-molotov para hacer estallar los lesbian and gay studies, los queer studies y todo intento de imitación de la cultura straight. [...] Ya no se trata de visibilidad, sino de vitalidad" (20). El presente dossier de InterAlia comparte la voluntad de incorporar las perspectivas gais, lesbianas,

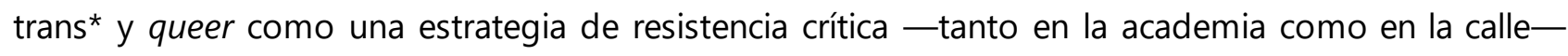
a las (o)presiones y violencias engendradas por el pensamiento heteropatriarcal. En la senda de otras colecciones y antologías previas, aspiramos a ofrecer una serie de reflexiones que continúen indagando cuerpos, discursos, fenómenos y representaciones a contracorriente del mandato heterosexual, tanto para evidenciar sus contradicciones y puntos ciegos, como para imaginar o provocar posibles fugas y empoderamientos.

Si bien la crítica LGTBQ latinoamericana comenzó a emerger prácticamente al mismo tiempo que la española -los estudios pioneros de David W. Foster (1991) sobre textos latinoamericanos y los de Paul J. Smith (1992) sobre literatura y cine españoles se publicaron con apenas un año de diferencia- no son pocas las divergencias entre los modos del activismo y la academia tal como se llevan a cabo en España y en Latinoamérica. Por este motivo, la convocatoria del presente dossier insistía en la necesidad de reforzar el diálogo y los intercambios entre todos los ámbitos hispanohablantes, más allá de fronteras geográficas específicas. El "entre otros/as" del título apuntaba, así, a una (deseable) pluralidad de miradas que sabíamos de antemano utópica: los trabajos finalmente reunidos en este número de InterAlia dan cuenta solo de algunos problemas, textos, debates y representaciones, pero confiamos en que se trata de aportes que enriquecerán el campo de estudios por su variedad y compromiso, tanto intelectual como ético.

Cuatro secciones principales conforman el dossier. La primera reúne nueve artículos seleccionados a partir del call por papers; la segunda, una serie de notas breves de investigadoras e investigadores a quienes invitamos a colaborar, con la certeza de que sus aportes serían relevantes en el marco de este número; la tercera sección propone un abandono momentáneo del cauce más estrictamente académico, para descubrir, con Elena Madrigal, algunos recovecos literarios del deseo lesbiano; para degustar —en la pluma Spanglish de Susana Chávez-Silverman y en la lengua loca y enloquecida de Alejandro Modarelli- dos ejemplos de crónica latinoamericana decididamente torcida; para recorrer, finalmente, de la mano de Javier Sáez, las hipotéticas estaciones LGTBQ de la ciudad de Madrid, en un homenaje a las figuras que, desde las más diversas épocas y latitudes, han hecho una contribución significativa a las comunidades disidentes de lesbianas, maricas, trans*, bisexuales, intersex, queers... Por eso ese mapa, aunque madrileño, podría haberse desplegado en Barcelona, o Buenos Aires, o Santiago de Chile, o Río de Janeiro, o Ciudad de México: su objetivo no es otro que recordar(nos) unos tránsitos y unas luchas que nos conciernen a todos/as, independientemente de nuestra localización particular. Finalmente, se incluye una serie de reseñas de diferentes libros vinculados con el estudio del género y la sexualidad en España y Latinoamérica, a fin de ofrecer un panorama de la bibliografía recientemente aparecida. 
El azar de las propuestas recibidas a partir del call for papers coincidieron en una concentración geográfica polarizada entre Argentina y España; los artículos escogidos no ilustran, en consecuencia, la enorme diversidad de las perspectivas queer en el ámbito hispanohablante, sino que se concentran en realidades y manifestaciones específicas de esos dos países. La parcialidad de este enfoque puede valorarse, sin embargo, positivamente, porque favorece un acercamiento a dos ámbitos de pensamiento y acción muy ricos, que han mantenido y mantienen, además, no pocos contactos e intercambios, tanto desde la perspectiva cultural como desde el activismo o la academia.

Algunos artículos centran su atención en textos culturales, ampliamente definidos. Así, Romina Smiraglia valora las posibilidades de un cine queer argentino a partir de dos películas que (re)presentan sexualidades intersex: XXY (Lucía Puenzo, 2007) y El último verano de la boyita (Julia Somolonoff, 2009); mientras que Jorge Pérez explora el motivo de la niñez queer en películas de Carlos Saura y Jaime de Armiñán estrenadas en la década de 1970. Las infancias queer reaparecen en el estudio que Francisco Lemus consagra a la obra de tres artistas plásticos argentinos nucleados en el Centro Cultural Rojas de la ciudad de Buenos Aires. Los/as niñas y jóvenes analizados/as en estos trabajos desafían e impugnan las lógicas heterosexistas; resulta sugerente, por lo tanto, que otros dos artículos se aproximen, por vías muy diversas, a la problemática de la educación con perspectiva de género: si Irene Escudero Ledesma postula algunas alternativas pedagógicas con anclaje en la teoría queer, Juan Péchin traza una genealogía política de las apropiaciones argentinas de dicha teoría, a fin de mostrar cómo se articulan los activismos sociales con los circuitos de producción y legitimación de saberes sobre género y sexualidad.

Los trabajos de Elena Castro y Marcin Kołakowski hacen pie en la literatura, para demostrar que se trata de un terreno ciertamente inestable cuando los cuerpos y deseos mostrados no acatan las normas de sexo-género: Castro indaga la obra de dos poetas españoles, José Infante y Txus García, quienes "entrometen" en sus textos a sujetos que no solo rechazan las imposiciones del pensamiento dualista heteronormativo, sino también la naturalización de identidades gay/lesbiana - avalada por propio colectivo LGTBQ. Kołakowski, por su parte, examina la presencia de signos feministas, lesbianos y queer en dos novelas de Lucía Etxebarria, mediante una minuciosa caracterización de los personajes que las protagonizan, no solo mujeres "lesbianas" sino también "heterosexuales", pero que desobedecen las normas patriarcales y se ubican más allá del binomio homo-hetero.

Los últimos dos artículos de este apartado asumen una perspectiva teórica con el objetivo de iluminar una problemática concreta: Blas Radi recurre a los estudios trans* y a la teoría decolonial para ofrecer una crítica de uno de los textos más influyentes y citados en el entorno queer hispanohablante: Testo Yonqui (2008) de Paul B. Preciado. El autor señala la gramática colonial que subyace a esta obra y que contribuye a la apropiación y borramiento de las personas trans*; este enfoque particular le permite reflexionar, en un sentido más amplio, sobre los límites del "pensamiento emancipatorio queer". Moira Pérez se ubica en el campo de la filosofía queer de la historia, para valorar cómo se forjan imágenes del pasado $-\mathrm{y}$ con qué objetivos-. Específicamente, la autora estudia los mecanismos de producción de representaciones de víctimas 
del terrorismo de Estado durante la última dictadura militar argentina. No pretende resolver las ansiedades políticas que genera este pasado, sino ingresar de plano en su riqueza y complejidad, abrazando las diferencias y ambigüedades de sus protagonistas y de nosotros/as mismos/as, en tanto sus herederos/as históricos/as.

La sección de notas breves compone un mosaico tan diverso como los temas, perspectivas y autores/as involucrados/as en cada una de ellas. La teoría se manifiesta en una doble vertiente: la recuperación, por parte de David W. Foster, de un texto fundacional del brasileño Samuel Rawet, Homossexualismo: sexualidade e valor (1970); así como la valoración, por parte de José Amícola, de perspectivas construccionistas en el abordaje de identidades y sexualidades pasadas. Las aproximaciones históricas a la otredad sexual vuelven a hacerse presentes en el trabajo de Carlos

Laiño Domínguez y José Antonio Ramos Arteaga, quienes reflexionan sobre la posibilidad de un contra-archivo queer en Canarias a partir de las huellas de disidencia sexual que dejó el irlandés Roger Casement en los diarios de su paso por las islas.

La vitalidad y riqueza de las expresiones culturales queer se manifiesta en múltiples frentes: Juan Vicente Aliaga revela la escena transfeminista española de la primera década del siglo XXI a través de sus producciones performáticas y videográficas; Chris Perriam ensaya una aproximación a una serie de cortometrajes de Juanma Carrillo desde las nociones de "vergüenza" y "vindicación"; María Teresa Vera Rojas y Antonio Caballero Gálvez indagan la representación cinematográfica de infancias y adolescencias fuera de la norma: en el primer caso, mostrando los usos queer del tiempo y del espacio de las protagonistas chicanas del film Mosquita y Mari (Aurora Guerrero, 2008); en el segundo, desvelando los mecanismos de construcción del niño disidente en Pa negre (2010) de Agustí Villaronga. Brad Epps y Alberto Mira, por su parte, revisitan dos "clásicos" del contra-canon literario español LGTBQ, Esthers Tusquets y Terenci Moix. Epps da cuenta de la oscilante recepción de la primera novela de Tusquets, El mismo mar de todos los veranos (1978), sin soslayar sus propias reacciones -intelectuales y emotivas - a ese texto pionero; mientras que Mira esboza dos posibles ejes de análisis de los volúmenes autobiográficos de Moix reunidos en $E l$ peso de la Paja (1990-1998): el proceso de crecer (o devenir) gay, tal como es representado en la escritura, y el posible impacto, en dicho proceso, de referencias cinematográficas y puntos de identificación. Otra incursión literaria, la de Humberto Guerra, nos traslada a México y a las representaciones de lo trans*; tras un breve panorama de abordajes del tema en diferentes medios artísticos - así como en la producción académica - Guerra presenta una lectura de la novela Travesti (2009) de Carlos Reyes Ávila, en la que detecta un cuestionamiento - pero también una reafirmación- de los valores patriarcales y de su violencia simbólica.

Completan la sección dos notas cuyo objetivo común es ofrecer un estado de la cuestión en torno a los alcances $-\mathrm{y}$ retos pendientes - de investigaciones LGTBQ. Mauricio List pone en perspectiva la producción mexicana sobre diversidad sexual y de género y destaca las líneas teóricas trabajadas en un amplio repertorio de disciplinas (sociología, antropología, psicología, etc.). Ese rastreo le permite dar cuenta de tendencias dominantes, logros y desafíos por venir; así como poner de relieve las posibilidades y los límites de este tipo de investigación en ámbitos universitarios no siempre favorables a su desarrollo. Alfredo Martínez Expósito, finalmente, despliega una 
cartografía de los estudios consagrados a la homofobia tanto en España como en Latinoamérica. Se trata, para el autor, de uno de los temas más acuciantes de la actualidad, pero menos atendido en las agendas académicas. La persistencia y el recrudecimiento de actitudes homofóbicas incluso en contextos con legislación protectora de derechos LGTBQ - exige una reflexión urgente por parte de los/as investigadores/as, en la senda de importantes antecedentes que Martínez Expósito releva con atención. Este llamado de atención sobre un conflicto con múltiples ramificaciones e impacto social, implica una necesidad puesta de relieve en otras notas y artículos del presente dossier: la de seguir acortando la brecha entre la academia y el activismo, entre la reflexión intelectual y la acción callejera; una invitación, en definitiva, a imaginar y producir otros modos de ser y estar juntos.

\section{Referencias bibliográficas}

Amícola, José, ed. "Lecturas queer desde el Cono Sur". Lectures du Genre 4 (2008). Web. 10 mayo 2017 <http://goo.gl/2kanV>.

Balderston, Daniel. El deseo, enorme cicatriz luminosa. Ensayos sobre homosexualidades latinoamericanas. Rosario: Beatriz Viterbo, 2004. Impreso.

Balderston, Daniel y Donna Guy, eds. Sex and Sexuality in Latin America. New York-London: New York UP, 1998. Impreso.

Balderston, Daniel y José Quiroga. Sexualidades en disputa. Homosexualidades, literatura y medios de comunicación en América Latina. Buenos Aires: Libros del Rojas, 2005. Impreso.

Balutet, Nicolas, ed. Ars Homoerotica: Escribir la homosexualidad en las letras hispánicas. Paris: Publibook, 2006. Impreso.

Bergmann, Emilie L. y Paul Julian Smith, eds. ¿Entiendes? Queer Readings, Hispanic Writings. Durham-London: Duke UP, 1995. Impreso.

Chávez-Silverman, Susana y Librada Hernández, eds. Reading and Writing the Ambiente. Queer Sexualities in Latino, Latin American and Spanish Culture. Madison: U of Wisconsin P, 2000. Impreso.

Córdoba García, David. "Teoría queer: reflexiones sobre sexo, sexualidad e identidad. Hacia una politización de la sexualidad". Teoría Queer. Políticas Bolleras, Maricas, Trans, Mestizas. Eds. David Córdoba, Javier Sáez y Paco Vidarte. Barcelona-Madrid: Egales, 2005. 21-66. Impreso.

Epps, Brad. "Retos, riesgos, pautas y promesas de la teoría queer". Revista Iberoamericana LXXIV 225 (2008): 897-920. Impreso.

Foster, David William. Ensayos sobre culturas homoeróticas latinoamericanas. Ciudad Juárez: Universidad Autónoma de Ciudad Juárez, 2009. Impreso.

------. Gay and Lesbian Themes in Latin American Writing. Austin: U of Texas P, 1991. Impreso. ed. Latin American Writers on Gay and Lesbian Themes: A Bio-Critical Sourcebook. Westport: Greenwood, 1994. Impreso.

. Producción cultural e identidades homoeróticas. San José de Costa Rica: Universidad de San José de Costa Rica, 2000. Impreso. 
Foster, David William y Roberto Reis, eds. Bodies and Biases. Sexualities in Hispanic Cultures and Literatures. Minneapolis: U of Minnesota P, 1996. Impreso.

Giorgi, Gabriel. Sueños de exterminio. Homosexualidad y representación en la literatura argentina. Rosario: Beatriz Viterbo, 2004. Impreso.

Ingenschay, Dieter, ed. Desde aceras opuestas. Literatura/Cultura gay y lesbiana en Latinoamérica. Madrid-Frankfurt: Iberoamericana-Vervuert, 2006. Impreso.

Kaminsky, Amy. "Hacia un verbo queer". Revista Iberoamericana LXXIV 225 (2008): 879-95. Impreso.

Llamas, Ricardo. Teoría torcida. Prejuicios y discursos en torno a "la homosexualidad". Madrid: Siglo XXI, 1998. Impreso.

López Penedo, Susana. El laberinto queer. La identidad en tiempos de neoliberalismo. BarcelonaMadrid: Egales, 2008. Impreso.

Maristany, José Javier. "Del pudor en el lenguaje. Notas sobre lo queer en Argentina". Lectures du Genre 10 (2013): 102-11. Web. 10 mayo 2017 <http://goo.gl/w1s8nG>.

Martinelli, Lucas, comp. Fragmentos de lo queer. Arte en América Latina e Iberoamérica. Buenos Aires: Editorial de la Facultad de Filosofía y Letras-Universidad de Buenos aires, 2016. Impreso.

Martínez, Luciano, ed. "Los estudios lésbicos-gays y queer latinoamericanos". Revista Iberoamericana LXXIV 225 (2008): 861-1162. Impreso.

Martínez Expósito, Alfredo, ed. "Gay \& Lesbian Writing in the Hispanic World". Antípodas. Journal of Hispanic Studies of the University of Auckland. Auckland: VOX-AHS, 1999/2000. Impreso.

Mérida Jiménez, Rafael M., coord. "Queerencias. Literaturas Hispánicas y Estudios LGTBQ (dossier monogràfic)". Lectora: Revista de Dones i Textualitat 17 (2011): 9-154. Impreso.

. ed. Sexualidades transgresoras. Una antología de estudios queer. Barcelona: Icaria, 2002. Impreso.

Mira, Alberto. De Sodoma a Chueca. Una historia cultural de la homosexualidad en España en el siglo XX. Barcelona-Madrid: Egales, 2004. Impreso.

Mogrovejo, Norma. Un amor que se atrevió a decir su nombre: la lucha de las lesbianas y su relación con los movimientos homosexual y feminista en América Latina. México DF: Plaza y Valdés, 2000. Impreso.

Molloy, Sylvia. Poses de fin de siglo. Desbordes del género en la modernidad. Buenos Aires: Eterna Cadencia, 2012. Impreso.

Molloy, Sylvia y Robert McKee Irwin, eds. Hispanisms and Homosexualities. Durham-London: Duke UP, 1998. Impreso.

Pertusa, Inmaculada. La salida del armario: lecturas desde la otra acera. Esther Tusquets, Carme Riera, Sylvia Molloy, Cristina Peri Rossi. Gijón: Llibros del Pexe, 2005. Impreso.

Quiroga, José. Tropics of Desire. Interventions from Queer Latino America. New York-London: New York UP, 2000. Impreso.

Richard, Nelly. Feminismo, género y diferencia(s). Santiago de Chile: Palinodia, 2008. Impreso. 
Richmond Ellis, Robert. "Introduction". Reading and Writing the Ambiente. Queer Sexualities in Latino, Latin American, and Spanish Culture. Eds. Susana Chávez-Silverman y Librada Hernández. Madison: U of Wisconsin P, 2000. 3-18. Impreso.

Rivas San Martín, Felipe. "Diga 'queer' con la lengua afuera. Sobre las confusiones del debate latinoamericano". Por un feminismo sin mujeres. Santiago de Chile: Coordinadora Universitaria por la Disidencia Sexual, 2011. 59-75. Impreso.

Rodríguez, lleana, ed. Cánones literarios masculinos y relecturas transculturales. Lo transfemenino/masculino/queer. Barcelona: Anthropos, 2001. Impreso.

Sánchez-Pérez, Gema. Queer Transitions in Contemporary Spanish Culture. From Franco to La Movida. New York: State University of New York P, 2007. Impreso.

Sibbald, Kay y Rosalía Cornejo Parriego, eds. "Un espacio queer. Queer Space". Revista Canadiense de Estudios Hispánicos 35.1 (2010): 1-263. Impreso.

Smith, Paul Julian. Laws of Desire: Questions of Homosexuality in Spanish Writing and Film, 19601990. Oxford: Clarendon, 1992. Impreso. (Versión castellana: Las leyes del deseo. La homosexualidad en la literatura y el cine español 1960-1990. Trad. Teresa Bladé. Barcelona: Ediciones de la Tempestad, 1998).

Solá, Miriam. "Introducción. Pret-textos, con-textos y textos". Transfeminismos. Epistemes, fricciones y flujos. Comps. Miriam Solá y Elena Urko. Tafalla: Txalaparta, 2013. 15-27. Impreso.

Sutherland, Juan Pablo. Nación marica: prácticas culturales y crítica activista. Santiago de Chile: Ripio Ediciones, 2009. Impreso.

. ed. Ficciones políticas del cuerpo. Lecturas universitarias de género, sexualidades críticas y teoría queer. Santiago de Chile: Editorial Universitaria, 2017. Impreso.

Trujillo, Gracia. Deseo y Resistencia: treinta años de movilización lesbiana en el Estado español (19772007). Barcelona-Madrid: Egales, 2009. Impreso. 